\title{
Optimal planning for developing, modernizing and maintaining the street infrastructure of dense and large urban areas
}

\author{
M. Popa, S. Raicu, E. Rosca \& D. Costescu \\ Transportation Faculty, University Politehnica of Bucharest, Romania
}

\begin{abstract}
This paper presents an optimisation model for scheduling works on urban street infrastructure. Using real traffic data from Bucharest, we analyse the exceeding of users' costs, as the difference between the users' total costs on a simplified network without works and the users' total costs in cases of various strategies of work completion. Due to the significant amount of users' costs they have to be considered beside the construction costs in selecting the best scheduling strategy. The constructor's costs are presented in three situations: (i) - the route, including several streets, is totally closed, there is a sole constructor working on the entire route and the streets are opened to traffic simultaneously; (ii) - the route is executed subsequently, each street being opened to traffic as the works on it are finished; (iii) all works start simultaneously, each street having its own construction site and the streets are opened to traffic as the works are finished. The total social cost, as a sum of users' additional costs and constructor's costs for the three strategies, represents the objective function for the optimal works scheduling on urban street infrastructure.

Keywords: users' additional costs, road construction costs, public auctions for infrastructure works, planning strategy, discount of total social costs.
\end{abstract}

\section{Introduction}

For a long period, the Bucharest City Hall did not have the necessary funds to make the transport infrastructure improvements/maintenance/developments for all kinds of urban transport networks (streets, tramway, trolleybuses, and tubes). In 2006, the total surface of the Bucharest street network was about 19500 
thousand square metres, with a total length of about $1900 \mathrm{~km}$, and only about $46 \%$ of this surface has asphalt or concrete pavement. The rest of the streets are in poor condition.

Nowadays, the available funds for the needs of the transport infrastructure are quite impressive because of the Romania's U.E. integration. The decision makers initiate a large number of infrastructure projects, but unfortunately without a rigorous planning. We expect to have many simultaneous street working sites and many travelling troubles because of that, in the near future.

This paper represents the partial results of the research made by the Research Centre in Transportation University POLITEHNICA of Bucharest, funded by the Romanian Ministry of Research and Education through the National University Research Council.

The issue of planning the interventions to street infrastructure in large urban areas has stirred the scientists in transportation engineering since the 1960s. Thus, contributions provided by Ridley [1], Roberts and Funk [2], Stairs [3] could be outlined. All planning methods revealed the difficulties of evaluating and synthesizing urban networks. The recent literature contains contributions proposed by Manoj et al. [4], Chen et al. [5], Hegazy et al. [6] oriented to identify modern methods and algorithms to solve scheduling infrastructure maintaining activities.

The present paper analyses two divergent interests: one of the users (which want to have the shortest periods of works) and, on the other side, the entrepreneur interest, to have the largest works field and therefore, to have the smallest unit costs, without time (or with a little) concerns.

We prove the necessity of scheduling the maintaining activities of street infrastructure in large urban areas, using a small network of radial-circular shape and three different working strategies, taking into account the total social costs (users' costs and the entrepreneur's costs). Each stage of the schedule is defined as the required completion period for a sole link delimited by two neighbour nodes (intersections).

We organize this paper as follows: the next section is dedicated to the users' additional costs assessment taking into account the no-projects users' costs and with-projects users' costs, and in the third section, we present different strategies to make a certain type of infrastructure works, and the entrepreneur's costs and also the users' additional costs. In the fourth section we discuss the optimal strategies to follow up providing the minimum total social costs during the working period. We present the conclusions in a concise manner, able to persuade political factors on rigorous planning of working activities on urban street networks.

\section{Users' costs}

\subsection{Street network structure in historical cities}

In opposition to "new cities" having a "grid" structure of street networks, such as those from central and western part of the USA or those from Australia, in "old cities" from Europe, with long historical evolution, the street networks are 
hybrid, in most cases having a radial-circular shape. Such cities present a central plaza with spokes extending from the centre, and circular streets connecting these spokes, fig. 1.

Bucharest is also a city with historical evolution. In the beginning it was extended on a river shore, then incorporated both shores (as Vienna, Budapest, Paris etc). A main route from North to South is observed, having the greatest transit capacity, but also another one from East to West. The graph depicted in figure 1 is used for modelling the street network of such a historical city. The graph links have various lengths, capacities and cost functions. Without affecting the generality, four length categories are considered: $l_{3}>l_{2}>l_{1}>l_{0}$.

The streets are classified in four categories, starting from the current situation in Bucharest, but any other taxonomy is allowed (once more the model generality is preserved).

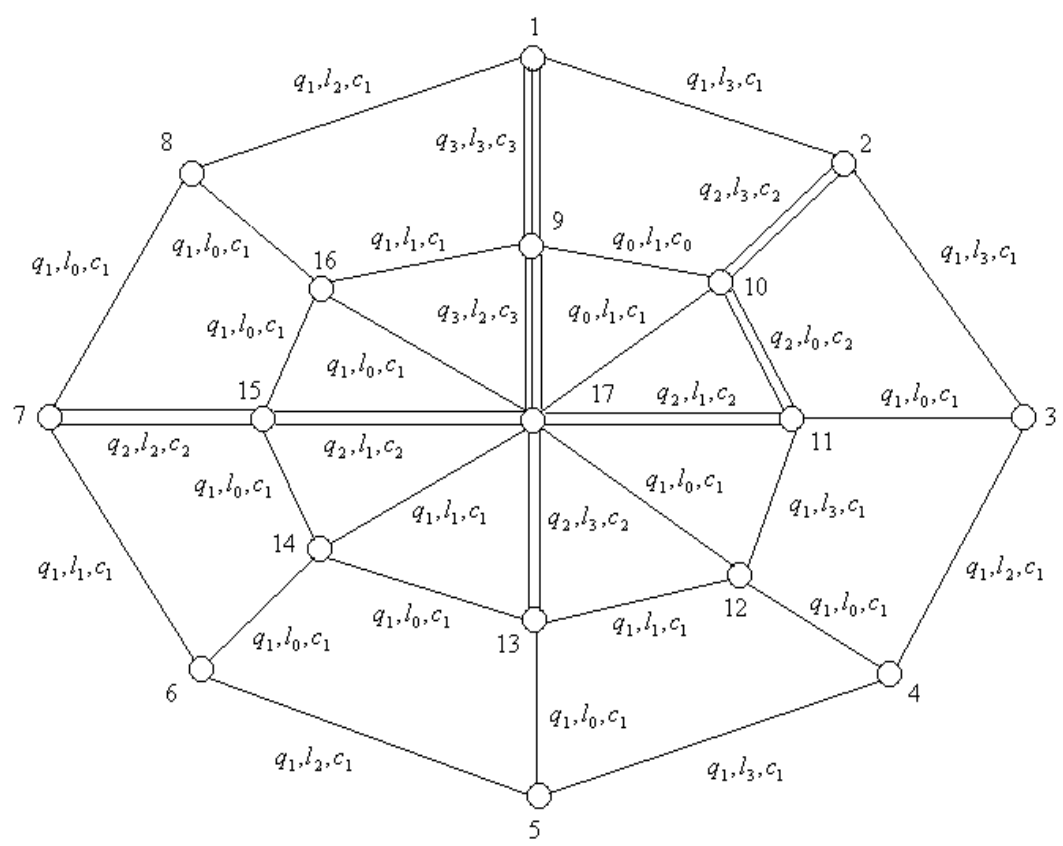

Figure 1: $\quad$ Simple radial-circular street network $\left(q_{i}-\right.$ capacity, $l_{i}-$ length, $c_{i}-$ cost function).

The links characteristics are shown in table 1 .

\subsection{User's costs assessment}

The users' costs function, per $\mathrm{km}$ and hour, is:

$$
c_{i}=c_{0 i}+\alpha\left(f_{i} / q_{i}\right)^{7}\left[10^{-2} \mathrm{EUR} / \mathrm{km} / \mathrm{h}\right],
$$


where $c_{i}$ - the utilization cost per $\mathrm{km}$ and hour for a passenger car unit ( $\mathrm{pcu}$ ) in average conditions; the exponent 7 was selected according to literature (Steenbrink [7]), adding a surplus of 2 units to the 5 recommended, for outlining some external effects generated by car traffic;

$\mathrm{c}_{0 \mathrm{i}}$ - the free flow utilization cost, related to the link type and capacity (influenced by the maximum legal speed) for a passenger car unit (pcu);

$\alpha$ - coefficient whose level balances the standard trip time value during the working day hours with the travel lost time value of an average driver in Bucharest (Popa [8]).

The O-D matrix depicted in table 2 provides the number of pcu during the average hour of the working day $[\mathrm{pcu} / \mathrm{h}]$. The trips are assigned on the network itineraries, using an incremental traffic assignment method (Ortuzar and Willumsen [9]), assessing the users' costs when no project is carried on the street network, in a first step. The total users' cost during the average hour is $c_{h}=11,700$ EUR/h for the test data in table 2 ("no-project" hypothesis).

Table 1: $\quad$ Links characteristics.

\begin{tabular}{|l|c|c|}
\hline \multicolumn{1}{|c|}{ Type } & Capacity [pcu/h/sense] & $\begin{array}{c}\text { Unit users' costs function } \\
{\left[10^{-2} \mathrm{EUR} / \mathrm{km} / \mathrm{h}\right]}\end{array}$ \\
\hline $\begin{array}{l}\text { Three or more lanes per } \\
\text { way }\end{array}$ & $6,000\left(\mathrm{q}_{3}\right)$ & $3+3.6\left(\mathrm{f} / \mathrm{q}_{3}\right)^{7}\left(\mathrm{c}_{3}\right)$ \\
\hline Two lanes per way & $4,000\left(\mathrm{q}_{2}\right)$ & $3.2+3.8\left(\mathrm{f} / \mathrm{q}_{2}\right)^{7}\left(\mathrm{c}_{2}\right)$ \\
\hline One lane per way & $2,000\left(\mathrm{q}_{1}\right)$ & $3.36+4.04\left(\mathrm{f} / \mathrm{q}_{1}\right)^{7}\left(\mathrm{c}_{1}\right)$ \\
\hline One way & $1,500\left(\mathrm{q}_{0}\right)$ & $3.36+4.04\left(\mathrm{f} / \mathrm{q}_{0}\right)^{7}\left(\mathrm{c}_{0}\right)$ \\
\hline
\end{tabular}

Table 2: $\quad$ O-D trips matrix.

\begin{tabular}{|c|c|c|c|c|c|c|c|c|c|c|c|c|c|c|c|c|c|}
\hline & 1 & 2 & 3 & 4 & 5 & 6 & 7 & 8 & 9 & 10 & 11 & 12 & 13 & 14 & 15 & 16 & 17 \\
\hline 1 & - & 200 & 100 & - & 100 & - & 300 & 200 & 500 & - & 300 & - & - & 100 & 100 & - & 1000 \\
\hline 2 & 500 & - & 400 & - & - & - & 700 & 800 & - & - & - & - & - & - & - & - & 300 \\
\hline 3 & 200 & - & - & 100 & 100 & - & 300 & 700 & 600 & 300 & 100 & - & - & - & 500 & 400 & 200 \\
\hline 4 & 500 & 300 & 100 & - & 100 & 100 & 200 & 500 & 100 & 100 & 100 & 100 & - & - & 200 & 200 & 200 \\
\hline 5 & 200 & 500 & 200 & - & - & 100 & 200 & - & 700 & 300 & 200 & - & 400 & - & - & 100 & 400 \\
\hline 6 & 400 & 600 & 300 & 100 & - & - & 100 & - & 300 & 400 & - & - & 100 & 100 & 100 & - & 300 \\
\hline 7 & 500 & 700 & 900 & 800 & 50 & 100 & - & 100 & 700 & 300 & 400 & 100 & 100 & 100 & 400 & 100 & 600 \\
\hline 13 & 300 & 800 & 200 & - & 100 & - & - & 500 & 300 & 200 & 300 & - & - & - & 300 & - & 400 \\
\hline 16 & 900 & 800 & 700 & 900 & 200 & 300 & 500 & 100 & 50 & 150 & 300 & 500 & - & 100 & - & - & 700 \\
\hline
\end{tabular}

In the case of working activities to the infrastructure, the users' costs is recomputed taking into consideration a new network structure, according to the adopted schedule of works (some of the network's links are closed).

We calculate the total users' additional costs on each month versus the nonproject users' costs, taking into account about 12 hours of average traffic per day, and about 20 working days per month. The total users' additional costs per 
month, in different cases of links closing, during infrastructure works, for example per 4 month, on the links sequence: $2-10-11-17-16$ (fig.1) are in table 3 .

The impressive amount of money lost by the users every month, when the infrastructure is in different working progress, requests the careful analysis of the working strategies, and the necessity to consider the users' cost beside the entrepreneur's costs.

Table 3: $\quad$ Examples of users' costs for different working strategies [EUR].

\begin{tabular}{|l|l|r|}
\hline \multirow{2}{*}{$\begin{array}{l}\text { users' costs for the whole } \\
\text { network, "no-works" }\end{array}$} & per average hour & 11,695 \\
\cline { 2 - 3 } & per month (working days) & $2,806,800$ \\
\hline $\begin{array}{l}\text { users' costs for the whole } \\
\text { network, in case of total closing } \\
\text { (2-10-11-17-16) }\end{array}$ & per average hour & 32,665 \\
\cline { 2 - 3 } & per month (working days) & $7,839,600$ \\
\cline { 2 - 3 } & per 4 month & $31,358,400$ \\
\hline $\begin{array}{l}\text { users' costs for the whole } \\
\text { network, in case of link 2-10 } \\
\text { closure }\end{array}$ & per average hour & 12,912 \\
\cline { 2 - 3 } & per month (working days) & $3,098,880$ \\
\hline $\begin{array}{l}\text { users' costs for the whole } \\
\text { network, in case of link 10-11 } \\
\text { closure }\end{array}$ & per average hour & 13,292 \\
\cline { 2 - 3 } $\begin{array}{l}\text { users' costs for the whole } \\
\text { network, in case of link 11-17 } \\
\text { closure }\end{array}$ & per average hour & 23,428 \\
\hline $\begin{array}{l}\text { users' costs for the whole } \\
\text { network, in case of link 17-16 } \\
\text { closure }\end{array}$ & per month (working days) & $5,622,720$ \\
\hline $\begin{array}{l}\text { users' costs for the whole network, in case of successive link } \\
\text { closing/opening }\end{array}$ & 18,838 \\
\cline { 2 - 3 } & per average hour & $4,521,120$ \\
\hline
\end{tabular}

\section{Building and users' costs during the works}

The current regulations in Romania provide public auctions for infrastructure intervening activities, having as the main award criteria the total building cost per length unit. It is possible that such regulations are presented in other European cities, but no investigation has been done in this way. To obtain the lowest costs per length unit, it is necessary to have a larger working length so that the construction site opening costs are recorded only once and the productivity (length per time unit) increases. This represents the entrepreneur's main interest. The construction costs $\mathrm{C}_{\mathrm{b}}$ are:

$$
C_{b}=C_{O}+c_{b} \times l,
$$

where $C_{O}$ represents the construction site opening costs, related to the infrastructure works type - developing, modernizing or maintenance works (Steenbrink [7]);

$\mathrm{c}_{\mathrm{b}}$ - the unit cost per one $\mathrm{km}$ of infrastructure, related to the working type and productivity;

1 - the auctioned length for building. 
The activity scheduling can be carried out on the following schemes, each one defined by the completion periods, users' costs and building costs.

Strategy I: A route, including several links (a sequence of streets), is built by a sole entrepreneur that records only once costs for opening the construction site; the links are built subsequently till the completion of the whole route and traffic opening. Figure 2 depicts on the y-axis the users' additional costs during the total traffic closing (e.g.: all three links are totally closed and simultaneously opened to traffic). In this case $C_{u}^{I}$ is the users' additional costs per month.

The entrepreneur's costs are given by eqn (2), where $l=l_{1}+l_{2}+l_{3}$ represents the length of the three links. The construction site opening costs are $\mathrm{C}_{\mathrm{O}}^{\mathrm{I}}$. The total completion time is:

$$
T^{I}=1 / \gamma,
$$

where $\gamma$ represents the building productivity $[\mathrm{km} / \mathrm{month}]$, considered constant for working activities of the same type.

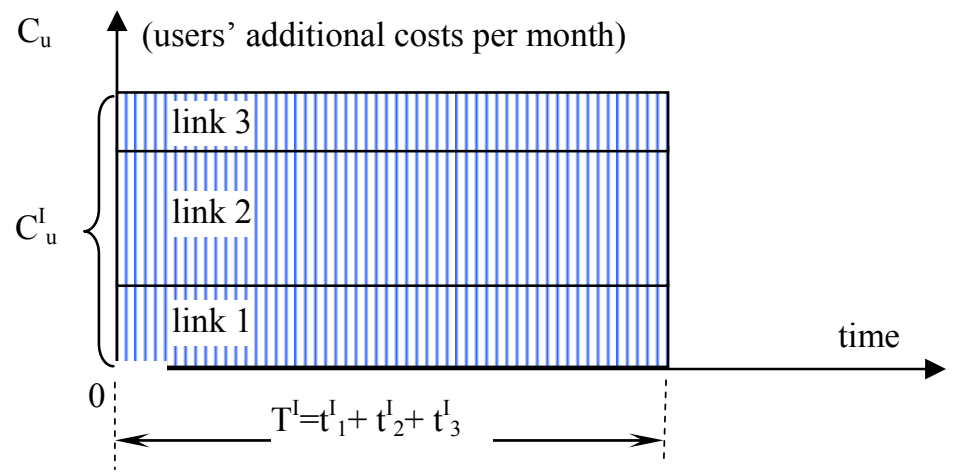

Figure 2: Users' costs for strategy I - one entrepreneur and a closed route containing a sequence of three consecutive streets.

Strategy II: The same route, including three consecutive links, is completed by the same entrepreneur that opens/closes the construction site for each link subsequently. After completing the works on a street (link), this one is opened to traffic. Figure 3 shows the users' costs for the second strategy and the completion times ( $\mathrm{C}_{\mathrm{ui}}^{\mathrm{II}}$ is the users' additional cost per month in case that link $i$ is closed and the others are open).

The entrepreneur costs are:

$$
C_{b}^{I I}=C_{O}^{I I}+c_{b} l_{3}+c_{b} l_{2}+c_{b} l_{1}=C_{O}^{I I}+c_{b} \gamma\left(t_{1}^{I I}+t_{2}^{I I}+t_{3}^{I I}\right),
$$

and $C_{O}^{I I}>C_{O}^{I}$.

Strategy III: The works are completed simultaneously; there are three construction sites opened at the starting time (by the same entrepreneur or by the three different entrepreneurs), fig. 4 . 


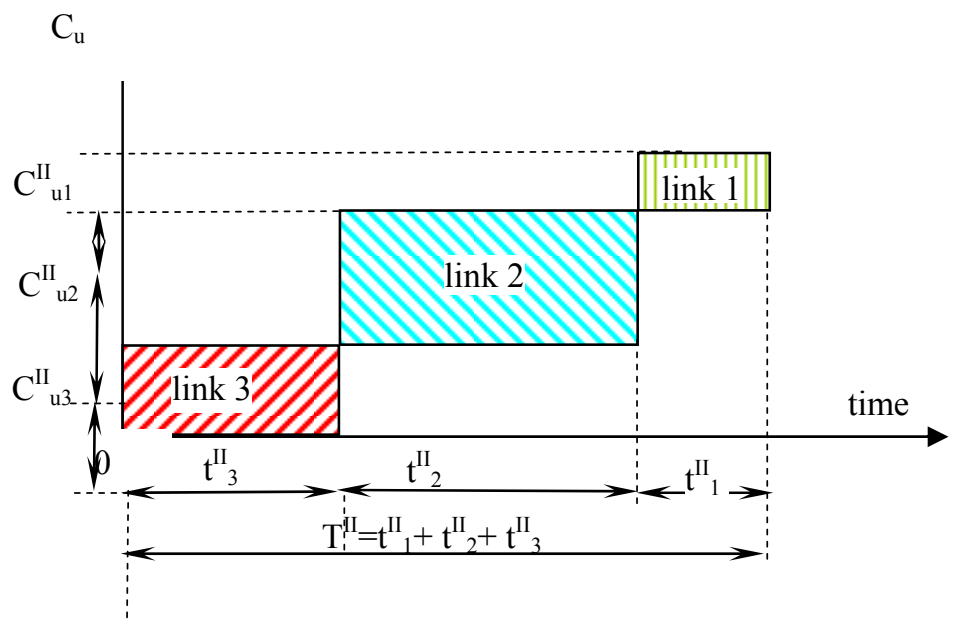

Figure 3: Users' costs for subsequently schedule of works on the route.

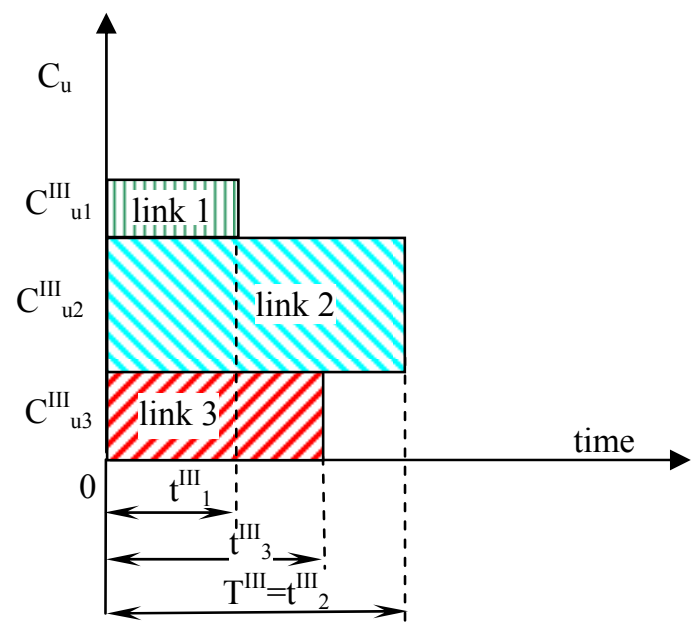

Figure 4: Users' costs for simultaneous completing of works on the links.

Each street (link) is opened to traffic after the completion of works. The total building costs are:

$$
\begin{aligned}
C_{b}^{I I I} & =C_{O 3}^{I I I}+c_{b} l_{3}+C_{O 2}^{I I I}+c_{b} l_{2}+C_{O 1}^{I I I}+c_{b} l_{1}= \\
& =C_{O 1}^{I I I}+C_{O 2}^{I I I}+C_{O 3}^{I I I}+c_{b} \gamma\left(t_{1}^{I I I}+t_{2}^{I I I}+t_{3}^{I I I}\right),
\end{aligned}
$$

and $C_{O 1}^{I I I}+C_{O 2}^{I I I}+C_{O 3}^{I I I}>C_{O 1}^{I I}+C_{O 2}^{I I}+C_{O 3}^{I I}>C_{O 1}^{I}$. 
In this model we consider constant working productivity, but usually, for some working types, a productivity enhancement could be achieved for greater working area.

\section{Optimal strategy for completing working activities}

Because the users' and entrepreneur's interests are divergent, the selection of the optimal strategy can be done taking into consideration the total social cost as the sum of the two costs (users and entrepreneur). The completion period extends over several months or years, therefore the discount of costs is mandatory. The social costs of the presented strategies, $S^{I}, S^{I I}$ and respectively $S^{\text {III }}$, are:

$$
\begin{aligned}
S^{I}= & \sum_{t=1}^{t_{1}^{I}+t_{2}^{I}+t_{3}^{I}} \frac{C_{u 1}^{I}+C_{u 2}^{I}+C_{u 3}^{I}}{(1+\Delta)^{t}}+\frac{C_{O}^{I}+c_{b} \gamma\left(t_{1}^{I}+t_{2}^{I}+t_{3}^{I}\right)}{(1+\Delta)^{t_{1}^{I}+t_{2}^{I}+t_{3}^{I}}}, \\
S^{I I}= & \sum_{t=1}^{t_{3}^{I I}} \frac{C_{u 3}^{I I}}{(1+\Delta)^{t}}+\sum_{t=t_{3}^{I I}}^{t_{3}^{I I}+t_{2}^{I I}} \frac{C_{u 2}^{I I}}{(1+\Delta)^{t}}+\sum_{t=t_{3}^{I I}+t_{2}^{I I}}^{t_{3}^{I I}+t_{2}^{I I}+t_{1}^{I I}} \frac{C_{u 1}^{I I}}{(1+\Delta)^{t}}+ \\
& \frac{C_{O}^{I I}+c_{b} \gamma t_{3}^{I I}}{(1+\Delta)^{t_{3}^{I I}}}+\frac{c_{b} \gamma t_{2}^{I I}}{(1+\Delta)^{t_{3}}+t_{2}^{I I}}+\frac{c_{b} \gamma t_{1}^{I I}}{(1+\Delta)^{t_{3}}+t_{2}^{I I}+t_{1}^{I I}} \\
S^{I I I}= & \sum_{t=1}^{t_{1}^{I I I}} \frac{C_{u 3}^{I I I}+C_{u 2}^{I I I}+C_{u 1}^{I I I}}{(1+\Delta)^{t}}+\sum_{t=t_{1}^{I I I}}^{t_{3}^{I I I}} \frac{C_{u 3}^{I I I}+C_{u 2}^{I I I}}{(1+\Delta)^{t}}+\sum_{t=t_{3}^{I I I}}^{t_{2}^{I I I}} \frac{C_{u 2}^{I I I}}{(1+\Delta)^{t}}+ \\
& \frac{C_{O 3}^{I I I}+c_{b} \gamma t_{3}^{I I I}}{(1+\Delta)^{t_{3} I I}}+\frac{C_{O 2}^{I I I}+c_{b} \gamma t_{2}^{I I I}}{(1+\Delta)^{t_{2}^{I I I}}}+\frac{C_{O 1}^{I I I}+c_{b} \gamma t_{1}^{I I I}}{(1+\Delta)^{t_{1}^{I I}}}
\end{aligned}
$$

where $\Delta$ is the discount rate.

We represent in fig. 5 the eqns (6)-(8) to show that we can estimate the optimal planning that provides the minimum total social costs for the street infrastructure works.

For a certain strategy, the same line pattern is used to represent the users' additional costs (horizontal lines) and the construction costs (oblique lines). The surface beneath the lines with the same pattern represents the total social cost for a certain strategy.

\section{Conclusions}

Infrastructure workings generate effects on users and externalities during their completion, according to their type (modernization, development or maintenance). The amount of users' costs is huge and they have to be taken into consideration in works scheduling. 


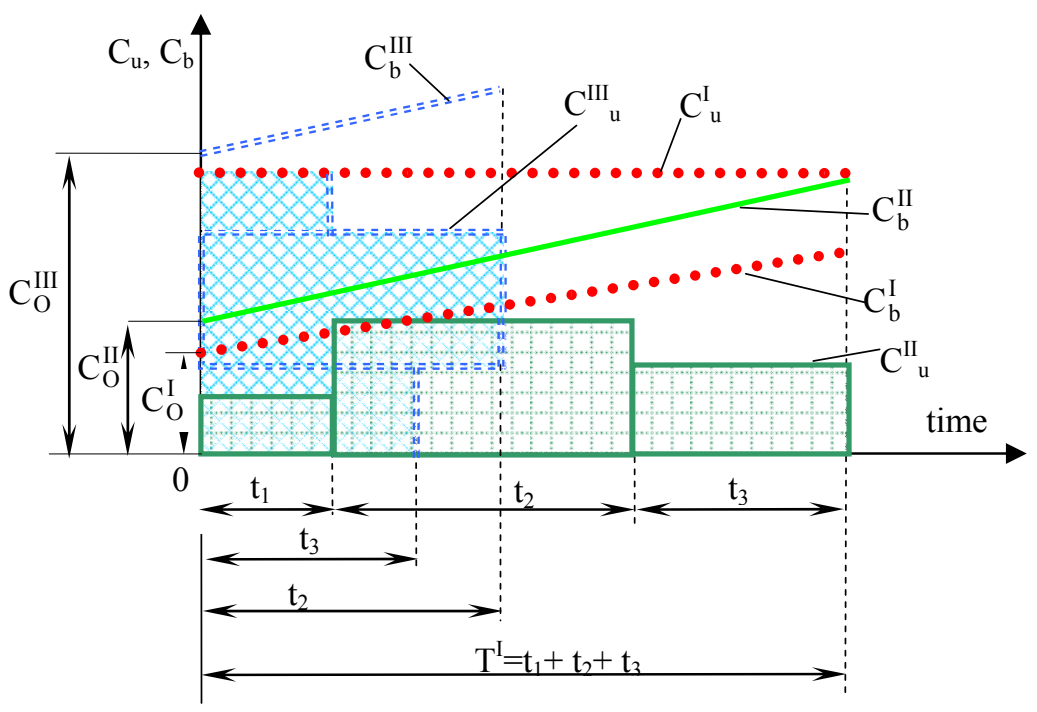

Figure 5: Total social cost for all planning strategies.

The paper concludes that the users' costs and the users' additional costs (as a result of workings) are significant for the European cities with historical evolution and radial-circular design of street network. The users' additional costs differ from one working scheduling strategy to another. As a result, the strategy and the selection of the entrepreneur should take into consideration the total social cost (the sum of users' additional costs and construction costs) estimated over the execution time. The users' costs are computed for the total closure of the streets included on a construction site.

The analysis could be extended by allowing the partial circulation on the streets under construction. Thorough estimations of the dependence between the cost function and the traffic flow/capacity ratio have to be done.

The paper investigates three strategies: (i) the total closure of a route, including several links, and the opening of the whole route at the end of all works; the construction costs are the smallest; (ii) subsequently closure of links (streets between two successive intersections) and their opening as soon as the works are completed on each link; the construction site moves to the next link and the fixed construction costs are higher; (iii) the closure of the entire route and simultaneous opening of three construction sites, each one on a link; the fixed construction costs are the highest. The effects of opening the traffic on half of the lanes from a link under construction have to be also analysed, taking into account the traffic congestion.

The analysis will be extended by considering the effects of opening new modernized routes that provide reduced users' costs. This aspect is determinant in setting the order of street works completion so as to obtain the lowest social cost. 


\section{References}

[1] Ridley, T.M., An investment policy to reduce travel time in a transportation network, Operation Research Centre report ORC 65-34, University of California: Berkeley, 1965.

[2] Roberts, P.O. \& Funk, M.L., Toward optimum method of link addition in transport networks, Department of Civil Engineering, MIT, 1964.

[3] Stairs, S., Selecting an optimal traffic network. Journal of Transport Economics and Policy, 2(2), pp. 218-231, 1968.

[4] Manoj, K.J., Kepaptsoglou, K., Karlaftis, M. \& Abdulah, J., A genetic algorithm-based decision support system for transportation infrastructure management in urban areas. Recent Advances in City Logistics, eds. E. Taniguchi \& R. Thompson, Elsevier: Amsterdam, pp. 532-541, 2006.

[5] Chen, R.L., Wang, Y. \& Fwa, T.F., Genetic Algorithm - Simulation Methodology for Pavement Maintenance Scheduling. Computer Aid Civil and Infrastructure Engineering, 19(6), pp. 446-455, 2004.

[6] Hegazy, T., Elhakeem, A. \& Elbeltagi, E., Distributed Scheduling Model for Infrastructure Networks. Journals of Construction Engineering and Management, 130(2), pp. 160-167, 2004.

[7] Steenbrink, P.A., Optimization of Transport Networks, John Wiley \& Sons: London, England, 1974.

[8] Popa, M., Elemente de economia transporturilor (Transport Economics Fundamentals), Bren Publishing House: Bucharest, 2004 (in Romanian).

[9] Ortúzar, J.D. \& Willumsen, L.G., Modelling Transport, John Wiley \& Sons: London, 2001. 